Proceedings of the 4th International Congress APMAS2014, April 24-27, 2014, Fethiye, Turkey

\title{
Manipulation of Exchange Coupling in Py/Co/Cr Multilayer Thin Films
}

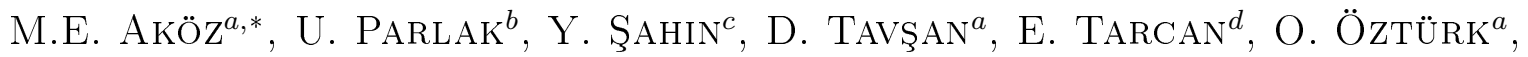 \\ S. TOKDEMIR ÖZTÜRK ${ }^{a}$, M. ERKOVAN ${ }^{e}$ \\ ${ }^{a}$ Gebze Technical University, Department of Physics, 41400, Kocaeli, Turkey \\ ${ }^{b}$ Peter Grünberg Institut, Electronic Properties (PGI-6), \\ Forschungszentrum Jülich, 52425 Jülich, Germany \\ ${ }^{c}$ Council of Forensic Medicine, 34196 Istanbul, Turkey \\ ${ }^{d}$ Kocaeli University, Department of Physics, 41380, Kocaeli, Turkey \\ ${ }^{e}$ Sakarya University, Department of Nanoscience and Nanoengineering, 54187, Sakarya, Turkey
}

\begin{abstract}
The main issue addressed in present study is exchange coupling modification between ferromagnetic layers through non-magnetic spacer layers using extra ultra-thin ferromagnetic layers (Co). In order to achieve this goal, we prepared $\operatorname{Cr}(50 \AA) / \operatorname{Py}(20 \AA) / \operatorname{Co}(5 \AA) / \operatorname{Cr}(7,10,13 \AA) / \operatorname{Co}(5 \AA) / \operatorname{Py}(30 \AA) / \operatorname{Cr}(50 \AA) / \operatorname{Si} u$ sing magnetron sputtering at UHV conditions and characterized by Ferromagnetic Resonance (FMR) technique. As the present study results were compared to our previous study on $(\mathrm{Py} / \mathrm{Cr})$, the exchange coupling energy was increased ten times with the cobalt thin layer
\end{abstract}

DOI: 10.12693/APhysPolA.127.992

PACS: 75.70.Cn, 75.50.Cc, 76.50.+g

\section{Introduction}

A magnetic multilayer structure is formed on a substrate as a periodic recap of ferromagnetic and "nonmagnetic" spacer layers. The magnetic multilayer structures exhibit rich and varied magnetic properties not observed from bulk material [1]. Especially after the discovery of antiferromagnetic coupling (or ferromagnetic coupling) between ferromagnetic layers over non-magnetic spacer metal layers in magnetic multilayer [2]. These coupling species and magnitude depend on the thickness of non-magnetic layer and control the magneto resistance of the multilayer system. Magnetic multilayer structures gained importance after GMR and TMR effects were observed in the late 1980s. After discovering GMR effect, P. Grünberg and A. Fert won the Nobel Prize in Physics in 2007.

Spin valve structures were developed with an additional antiferromagnetic (pinning) layer to observe GMR effect. It has brought enormous big technological impacts especially for data storage, data writing and reading [3].

However, there are still some problems in technological applications based on these effects. These problems arise when the bit size gets smaller and smaller. We focused on one of the problems which is the signal-noise ratio problem. In order to solve this problem, the large resistance difference has to be observed between two magnetization orientations (two states) from magnetic multilayer film system [4]. In order to increase the resis-

${ }^{*}$ corresponding author; e-mail: akoz@gyte.edu.tr tance between them, we proposed a new structure shown in Fig. 1. We claim that ultra-thin cobalt layer may change magnetic anisotropy and increase the resistance between two states. Besides, in order to obtain a significant GMR effect, the exchange interactions between FM layers through a NM metallic spacer must be antiferromagnetic [5].

\section{Sample preparation}

Samples were fabricated as $\operatorname{Cr}(50 \AA) / \operatorname{Py}(20 \AA) /$ $\mathrm{Co}(5 \AA) / \operatorname{Cr}(7,10,13 \AA) / \operatorname{Co}(5 \AA) / \operatorname{Py}(30 \AA) /$ $\mathrm{Cr}(50 \AA)$ on Si substrate by magnetron sputtering at UHV conditions. All of the samples were subjected to cleaning process and transferred into Ultra High Vacuum (UHV) conditions to annealing up to $600^{\circ} \mathrm{C}$ for $30 \mathrm{~min}-$ utes. For magnetron sputtering deposition, Ar process gas was used for base pressure decreasing to lower one while the growing process and it was controlled by mass flow controller, MKS 1179A. During the sputter deposition process, $\mathrm{Co}, \mathrm{Py}\left(\mathrm{Ni}_{80} \mathrm{Fe}_{20}\right)$, and $\mathrm{Cr}$ targets of three inches in diameter were used. Also, Quartz Crystal Monitoring (QCM) thickness monitor was used to observe deposition ratio in situ. The deposition rate of all materials were done by X-ray Photoelectron Spectroscopy (XPS). Sample thickness measured by QCM and photoemission attenuations calculated by XPS were the same $[6,7]$.

\section{Results}

The ferromagnetic resonance (FMR) was used to investigate magnetic properties of samples. FMR is one of the well-established and useful techniques [8-26] to investigate magnetic materials and to determine magnetic properties, such as magnetic anisotropy, magnetic moment, magnetic damping, etc. 

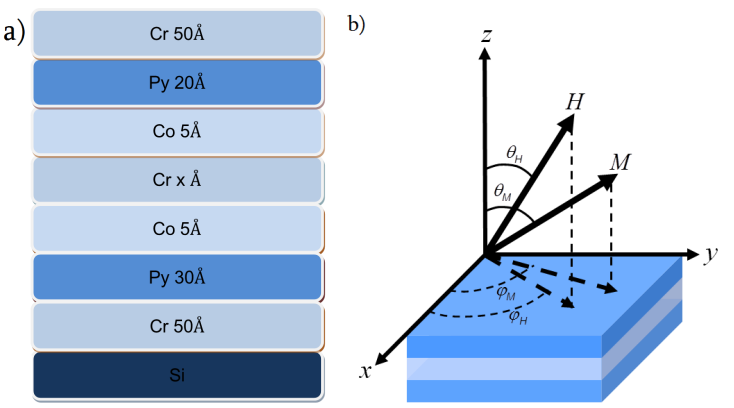

Fig. 1. a) Sample structure to investigate ultra-thin cobalt layer effecting on exchange coupling constant between ferromagnetic layers. b) Relative orientations of the external DC magnetic field and magnetization vectors with respect to the sample plane.

According to FMR results and theoretical models which details are seen in elsewhere, permalloy layers have in-plane magnetization in $\mathrm{Py} / \mathrm{Cr}$ bilayers [5], as shown in Fig. 2a.

On the other hand, ultrathin cobalt layers in $\mathrm{Py} / \mathrm{Co} / \mathrm{Cr}$ bilayers (Fig. 2b) have out-of-plane magnetization. Because of this difference, the exchange coupling constant $\left(A_{12}\right)$ changed from $0.010 \mathrm{erg} / \mathrm{cm}^{2}$ to $0.0320 \mathrm{erg} / \mathrm{cm}^{2}$ as the $\mathrm{Cr}$ spacer layer thickness was $1 \AA$. The value was calculated from FMR data with mathematical model.

a)

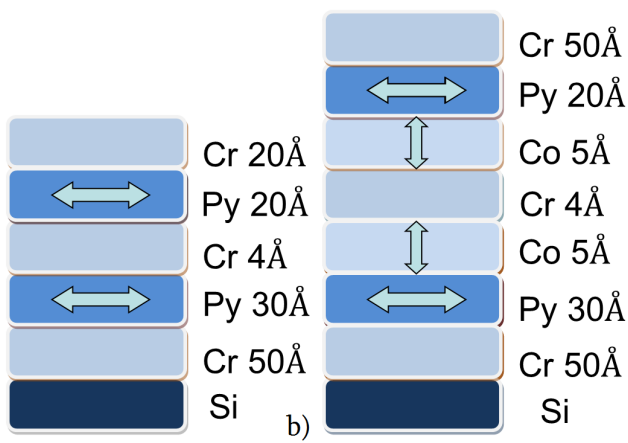

Fig. 2. a) The magnetic orientation of magnetic layers are in $\mathrm{Py} / \mathrm{Cr}$ system b) The magnetic orientation of magnetic layers are in $\mathrm{Py} / \mathrm{Co} / \mathrm{Cr}$ system.

Figure 3 shows FMR data and the mathematical model result for $10 \AA \mathrm{Cr}$. Ultra thin cobalt layer induced the exchange coupling constant but did not change the interaction specie between ferromagnetic layers.

We think that this increment arises from the magnetic orientation of cobalt layer and may play a very critical role for technological applications. Besides this changing for the exchange coupling, it increased saturation magnetization $\left(M_{S}\right)$ and the perpendicular anisotropy field $\left(H_{P}\right)$. Their comparison with $\mathrm{Py} / \mathrm{Cr}$ is given in Table I.

\section{Conclusion}

Consequently, the results were discussed for both $11 \AA$

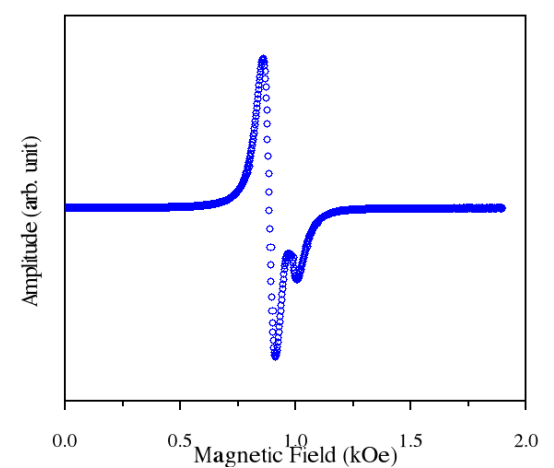

Fig. 3. Ferromagnetic resonance spectrum taken from 10 A Cr films at perpendicular geometry.

Comparing list of both with ultra-thin Co layer and without ultra-thin Co layer in $\mathrm{Py} / \mathrm{Cr}$ film systems $(10 \AA \mathrm{Cr})$

\begin{tabular}{c|c|c|c|c}
\hline \hline \multirow{2}{*}{} & \multicolumn{2}{|c|}{$\mathrm{Py} / \mathrm{Cr}$} & \multicolumn{2}{c}{ Py $/ \mathrm{Co} / \mathrm{Cr}$} \\
\cline { 2 - 5 } & $1^{\text {st }}$ Layer & $2^{\text {nd }}$ Layer & $1^{\text {st }}$ Layer & $2^{\text {nd }}$ Layer \\
\hline Type & $\mathrm{Py}$ & $\mathrm{Py}$ & Py+Co & $\mathrm{Co}+\mathrm{Py}$ \\
\hline Thickness & $20 \AA$ & $30 \AA$ & $20+5 \AA$ & $5+30 \AA$ \\
\hline$M_{S}$ & $600 \mathrm{G}$ & $600 \mathrm{G}$ & $775 \mathrm{G}$ & $785 \mathrm{G}$ \\
\hline$H_{P}$ & $350 \mathrm{G}$ & $350 \mathrm{G}$ & $3340 \mathrm{G}$ & $3340 \mathrm{G}$ \\
\hline$A_{12}$ & \multicolumn{2}{|c|}{$-0.0100 \mathrm{erg} / \mathrm{cm}^{2}$} & $-0.0320 \mathrm{erg} / \mathrm{cm}^{2}$ \\
\hline
\end{tabular}

Cr spacer layers with ultra-thin cobalt layer and without Cobalt layer, in our previous work. The interlayer exchange coupling parameter increases more than three times with respect to $\mathrm{Py} / \mathrm{Cr} / \mathrm{Py}$ structure when the second ultra-thin cobalt FM layer deposited. The second FM layer affects magnetic anisotropies of the film. The exchange parameter between FM layers can be also controlled by adding a second FM layer as Cobalt. This control mechanism with Co layer indicates new research and usage areas for sensor and data storage technologies.

\section{Acknowledgments}

This work was supported by Research Fund of Sakarya University, project number 2014-01-08-002.

\section{References}

[1] Magnetic Multilayers, edited by L.H. Bennett and R.E. Watson World Scientific, River Edge NJ, 1994.

[2] P. Grünberg, R. Schreiber, Y. Pang, M.B. Brodsky, H. Sowers, Phys. Rev. Lett. 57, 2442 (1986).

[3] C. Reig, M.D. Cubells-Beltran, D.R. Munoz, Sensors 9, 7919 (2009).

[4] R. Sbiaa, H. Meng, S.N. Piramanayagam, Physica Status Solidi Rapid Research Letters 5, 413 (2011).

[5] R. Topkaya, M. Erkovan, A. Öztürk, O. Öztürk, B. Aktaş, J. Appl. Phys. 108, 023910 (2010).

[6] M. Erkovan, Azarbaijan J. Phys. Fiz. XVI, 342 (2010). 
[7] M. Erkovan, M. Türksoy Öcal, O. Öztürk, Cornell University Library, arXiv:/1401.0227 (2010).

[8] B. Aktaş, R. Topkaya, M. Erkovan, M. Özdemir, Magnetic Characterization of Exchange Coupled Ultrathin Magnetic Multilayers by Ferromagnetic Resonance Technique in: Nanostructured Materials for Magnetoelectronics, Springer Series in Materials Science, 175, Berlin 2013.

[9] M. Erkovan, S.T. Öztürk, R. Topkaya, M. Özdemir, B. Aktaş, O. Öztürk, J. Appl. Phys. 110, 023908 (2011).

[10] P.E. Wigen, Z. Zhang, Braz. J. Phys. 22, 267 (1992).

[11] Z. Zhang, L. Zhou, P.E. Wigen, K. Ounadjela, Phys. Rev. Lett. 73, 336 (1994).

[12] B.Z. Rameev, A. Gupta, F. Yildiz, L.R. Tagirova, B. Aktas, J. Magn. Magn. Mater. 300, e526 (2006).

[13] N. Akdogan, B.Z. Rameev, L. Dorosinsky, H. Sozeri, R. Khaibullin, B. Aktaş, L. Tagirov, A. Westphalen, H. Zabel, J. Phys.: Condens. Matter 17, L359 (2005).

[14] S. Kazan, A. Cemil Başaran, B. Aktaş, M. Özdemir, Y. Öner, Physica B 403, 1117 (2008).

[15] B. Aktaş, B. Heinrich, G. Woltersdorf, R. Urban, L.R. Tagirov, F. Yildız, K. Özdoğan, M. Özdemir, O. Yalçin, B.Z. Rameev, J. Appl. Phys. 102, 013912 (2007).

[16] A.R. Köymen, L.R. Tagirov, R.T. Gilmutdinov, C. Topacli, C. Birlikseven, H.Z. Durusoy, B. Aktaş, IEEE Trans. Magn. 34, 846 (1998).
[17] B. Aktaş, Thin Solid Films 307, 250 (1997).

[18] B. Aktaş, M. Özdemir, Physica B 193, 125 (1994).

[19] B. Aktaş, Y. Öner, E.A. Harris, Phys. Rev. B 39, 528 (1989).

[20] G.D. Fuchs, J.C. Sankey, V.S. Pribiag, L. Qian, P.M. Braganca, A.G.F. Garcia, E.M. Ryan, Z.-P. Li, O. Ozatay, D.C. Ralph, R.A. Buhrman, Appl. Phys. Lett. 91, 062507 (2007).

[21] M. Farle, Rep. Prog. Phys. 61, 755 (1998).

[22] Z. Celinski, K.B. Urquhart, B. Heinrich, J. Magn. Magn. Mater. 166, 6 (1997).

[23] J.J. Krebs, P. Lubitz, A. Chaiken, G.A. Prinz, J. Appl. Phys. 67, 5920 (1990).

[24] C. Peng, C. Dai, D. Dai, J. Appl. Phys. 72, 4250 (1992).

[25] S.M. Rezende, C. Chesman, M.A. Lucena, A. Azevedo, F.M. de Aguiar, S.S.P. Parkin, J. Appl. Phys. 84, 958 (1998).

[26] M. Erkovan, S. Tokdemir Öztürk, D. Tşın Gaziğlu, R. Topkaya, O. Öztürk, Acta Physica Polonica A 124, 673 (2014). 